\title{
MusculoskeletalDisordersandTreatment
}

\section{Prevalence, Risk Factors and Health Care Service Utilization for Low-Back Pain among Nigerian Automobile Technicians}

\author{
Adesola Ojo Ojoawo ${ }^{1}$, Chidozie Emmanuel Mbada ${ }^{1}$, Timilehin Oladele ${ }^{1}$, Haruna Moda ${ }^{2}$, \\ Opeyemi Ayodiipo Idow ${ }^{3^{*}}$ (D), Ademola Sonuga ${ }^{1}$ and Francis Fatoye ${ }^{4}$
}

${ }^{1}$ Department of Medical Rehabilitation, Obafemi Awolowo University, Ile-Ife, Nigeria

${ }^{2}$ Department of Health Professions, Occupational Safety Health and Environment, Manchester Metropolitan University, Cavendish Street, Manchester, United Kingdom

${ }^{3}$ Department of Physiotherapy, School of Basic Medical Sciences, College of Medical Sciences, University of Benin, BeninCity, Nigeria

${ }^{4}$ Department of Health Professions, Faculty of Health, Psychology and Social Care, Manchester Metropolitan University, Manchester, United Kingdom

*Corresponding author: Opeyemi A Idowu, Ph.D., Department of Physiotherapy, School of Basic Medical Sciences, College of Medical Sciences, University of Benin, P.M.B 1154, Benin-City, Nigeria, Tel: +2347036872825

\section{Abstract}

Background: Automobile technicians in resource-limited countries depend more on manual than mechanized approach in their work, and as such, may be at high risk for musculoskeletal disorders such as low back pain (LBP). This study was aimed to investigate the prevalence, risk factors and health care service utilization for LBP among Nigerian automobile technicians.

Methods: A total of 240 members of the National Association of Automobile Technicians responded in this survey. A previously validated instrument on prevalence, risk factors and health-care-service utilization for LBP was adapted in this study. Data was analysed using descriptive and interferential statistics. Alpha level was set at $p<0.05$.

Results: Twelve-month and point prevalence of LBP were $79.2 \%$ and $75 \%$. On-going LBP was associated with work-related poor posture $(46.7 \%)$, trauma $(13.9 \%)$ and lifting of loads (11.7\%).

LBP mostly led to absenteeism from work $(46.8 \%)$ and consultation with health practitioners $(73.7 \%) .40 \%$ of respondents agreed to have incurred about N1000-N5000 as treatment cost, and $38.7 \%$ of the respondents lost about N5000-N10000 as estimated cost in terms of lost hours. Type of automobile activity engaged in $(p=0.483)$, frequent bending $(p=0.217)$, lifting objects weighing up to $5 \mathrm{~kg}(p=0.071)$ or up to $25 \mathrm{~kg}(p=$ $0.719)$ and sustained sitting $(p=0.349)$ or standing $(p=0.996)$ were not significantly associated with prevalence of LBP.
\end{abstract}

In the bivariate analysis, age $\left(X^{2}=3.298, P=0.192\right)$, marital status $\left(X^{2}=0.098, P=0.754\right)$, type of automobile repairs engaged in $\left(X^{2}=0.493, P=0.483\right)$, lifting objects up to 5 $\mathrm{kg}\left(x^{2}=3.269, p=0.071\right)$, lifting objects up to $25 \mathrm{~kg}\left(x^{2}=\right.$ $0.130, p=0.719)$, sustained sitting $\left(X^{2}=0.840, p=0.349\right)$, and sustained standing $\left(X^{2}=0.002, p=0.996\right)$ were not significantly associated with prevalence of LBP. Level of education $\left(X^{2}=6.121, p=0.047\right)$ was, however, associated with LBP prevalence, although this association was not sustained following logistic regression.

Conclusion: There is a high prevalence of LBP among Nigerian automobile technicians, and it results in work absenteeism, economic burden and increased need to seek health care.

\section{Keywords}

Low back pain, Automobile mechanics, Risk factor, Adults

\section{Abbreviations \\ LBP: Low Back Pain}

\section{Introduction}

Low-back pain (LBP) is a common cause of disability among the working population [1,2]. LBP alongside neck pain is ranked fourth in terms of disability-adjusted life years in the Global Burden of Disease 2016 study [3].

Citation: Ojoawo AO, Mbada CE, Oladele T, Moda H, Idowu OA, et al. (2021) Prevalence, Risk Factors and Health Care Service Utilization for Low-Back Pain among Nigerian Automobile Technicians. J Musculoskelet Disord Treat 7:092. doi.org/10.23937/2572-3243.1510092

Accepted: February 18, 2021: Published: February 20, 2021

Copyright: (C) 2021 Ojoawo AO, et al. This is an open-access article distributed under the terms of the Creative Commons Attribution License, which permits unrestricted use, distribution, and reproduction in any medium, provided the original author and source are credited. 
LBP usually develops over time, and it can be intense and become a reason for frequent work absenteeism and restrictions $[4,5]$, as well as, a cause for reduced quality of life and severe disability [6-8].

Low-back pain ranks among the most frequent conditions that are possible to be incurred during strenuous activities [9]. As such, rapid work pace and repetitive motion, forceful exertions, poor and prolonged body postures and vibration are often indicated as predisposing factors to LBP $[10,11]$. Earlier studies have sought to establish the prevalence of LBP among various occupational groups, including agricultural [12,13], construction [14,15], and health care $[16,17]$ workers. While some occupational groups have received considerable attention in literature, others, such as automobile technicians [1], whose works involve intense manual labour, especially in resource-limited settings are yet to gain the desired investigations.

Automobile mechanics play a central role in diagnosing and fixing automobile problems. However, this role comes with the need to maintain awkward positions for a long period; lift heavy spare parts, and in some instances require manoeuvring of the parts to get the repairs done. These work descriptions highlight that automobile technicians constantly exert physical strength at the detriment of their musculoskeletal health $[1,18,19]$. Therefore, this study was aimed to investigate the prevalence, risk factors and health care service utilization for LBP among Nigerian automobile technicians.

\section{Methods}

A cross-sectional survey of 240 registered members of National Association of Automobile Technicians, the coordinating association of automobile mechanics in $\mathrm{Ni}$ geria, was conducted. Individuals who had worked for more than a year before the commencement of this study, who could comprehend English or Yoruba language (a local language mostly spoken in South-west Nigeria), and have experienced LBP related to work exposure were included in the study. Automobile technicians who sustained any form of injury outside of auto mechanic duty with associated physical deformities (such as leg length discrepancy, scoliosis, and lordosis), and those with previous spinal surgery or with any form of back problem before they getting involved in automobile repair works were excluded from the study. Full disclosure on the purpose of the survey was given to eligible respondents, and their signed consents were obtained. Ethical approval was obtained from the Health Research and Ethics Committee (IPHOAU/12/723) of the Institute of Public Health, Obafemi Awolowo University, Ile-Ife, Nigeria.

Based on Cochran's sample formula [20], the sample size for this study was calculated, as shown below:

$n_{0}=\frac{z^{2} \times p \times q}{(e)^{2}}$
Where $\mathrm{n}_{0}$ is the sample size; $\mathrm{z}$-value is found in a $\mathrm{Z}$ table (1.96 for a confidence level of $95 \%$ ); $p$ is the (estimated) proportion of the population which has the attribute in question $(0.2)$; $q$ is $1-p(1-0.2=0.8)$ and $e$ is the desired level of precision (i.e. the margin of error = 0.05)

$$
n_{0}=\frac{(1.96)^{2} \times 0.2 \times(1-0.2)}{(0.05)^{2}}=246
$$

Based on the calculated sample size, a total of 246 automobile technicians were invited into the study, however, only 240 responded, yielding a response rate of $97.6 \%$.

This study adapted a survey instrument previously used by Bindra, et al. [21] to determine the prevalence, risk factors, impact, health care service utilization and back pain features. The instrument comprised of five sections. Section A considers demographic information (including age, level of education, marital status). Section B utilizes a pictorial diagram of the posterior view of a human being to extract information on pain pattern (including duration, nature, severity, and activities limited by the pain). Section $C$ seeks information on the primary outcomes such as prevalence and impact of LBP (cost implication and activity limitation as a result of pain) from the respondents in the past 12 months. Section D seeks information on the health care services utilization for LBP, while Section E was about physical factors at work that might predispose to LBP. In addition, the Visual Analogue Scale (VAS), in which the respondents select a number on a scale from 0-10 integers that represent their current pain was used to assess pain intensity in this study [22]. Both tools were self-administered among the respondents.

Descriptive statistics of frequency, percentage, mean and standard deviation were used to summarize the data. Chi-square test was used to determine associations between prevalence of LBP, and respondents' socio-demographic factors (age, marital status, level of education) and job factors (the type of automobile engaged in and most common work activity). Factors with $P$-value less than 0.25 were entered into logistic regression to identify the effect of the independent variables on the outcome variable (prevalence of LBP). The strength of the association was presented by odds ratio and $95 \%$ confidence interval. A p-value of $<0.05$ was considered statistically significant. Data analysis was conducted using SPSS Statistics for Windows, version 23 (IBM Inc., Armonk, NY).

\section{Results}

The mean age of the respondents ( $100 \%$ males) was $44.98 \pm 6.70$ years (age ranging from 30 to 63 years). Majority of respondents were within $40-49$ years age bracket $(52.1 \%)$ and married (82.5\%). All of the respondents $(100 \%)$ were involved in activities that required frequent bending at work. The socio-demographic pro- 
Table 1: Socio-demographic profile and job characteristics of the respondents.

\begin{tabular}{|c|c|c|}
\hline Variables & Frequency & Percentage \\
\hline \multicolumn{3}{|l|}{ Age } \\
\hline $30-39$ years & 59 & 24.6 \\
\hline $40-49$ years & 125 & 52.1 \\
\hline 50 years and above & 56 & 23.3 \\
\hline \multicolumn{3}{|l|}{ Marital status } \\
\hline Single & 24 & 10.0 \\
\hline Married & 198 & 82.5 \\
\hline Divorced & 18 & 7.5 \\
\hline \multicolumn{3}{|l|}{ Level of education } \\
\hline None & 14 & 5.8 \\
\hline Primary & 21 & 8.8 \\
\hline Secondary & 158 & 66.8 \\
\hline Tertiary & 47 & 19.6 \\
\hline \multicolumn{3}{|l|}{ Type of automobile engaged with } \\
\hline Small cars & 119 & 50.4 \\
\hline Big cars & 121 & 49.6 \\
\hline \multicolumn{3}{|l|}{ Most common work activity } \\
\hline Frequent bending & 240 & 100 \\
\hline Lifting objects up to $5 \mathrm{~kg}$ & 186 & 77.5 \\
\hline Lifting objects up to $25 \mathrm{~kg}$ & 105 & 43.8 \\
\hline Sustained sitting & 129 & 53.8 \\
\hline Sustained standing & 159 & 66.3 \\
\hline
\end{tabular}

file and job characteristics of the respondents are presented in Table 1.

The twelve-month prevalence of LBP among the respondents was $79.2 \%$. Single occurrence and one time or repeated recurrence of LBP in the past 12 months was $21.1 \%$ and $78.9 \%$. Continuous lower body movement associated with work-place activities had negative impact on the back (95\%) of respondents. Climbing stairs $(52.1 \%)$, standing $(48.8 \%)$, lying $(48.8 \%)$ and stooping $(45.8 \%)$ were the most affected activities by LBP during the past 12 months.

Eighty-nine (46.8\%) of the respondents who had LBP in the past one year were absent from work, while $52.7 \%$ were away from work for over a month. Cost implications and activity limitation resulting from LBP in the past 12 months is reported in Table 2. From the result, $40 \%$ and $35.8 \%$ of respondents agreed to have incurred about N1000-N5000 and N5000-N10000 respectively as treatment cost. Also, $35.5 \%$ and $38.7 \%$ of the respondents reported about N1000-N5000 and N5000-N10000 as estimated cost in terms of lost hours. $50.7 \%$ of the respondents had consulted a physiotherapist for their LBP (Table 3).

The point prevalence of LBP in this study was $75 \%$. Respondents who had LBP in the past seven days believed it was caused by poor posture (46.7\%), trauma (13.9\%), lifting of loads (11.7\%) and sudden movement

Table 2: Cost implications and activity limitation of respondents as a result of low back pain in the past 12 months.

\begin{tabular}{|c|c|c|}
\hline Variable & Frequency & Percentage \\
\hline \multicolumn{3}{|l|}{$(N=190)$} \\
\hline \multicolumn{3}{|l|}{ Cost of treatment of LBP (In Naira) } \\
\hline No cost & 6 & 3.2 \\
\hline Less than N1000 & 40 & 21.1 \\
\hline N1000-N5000 & 76 & 40.0 \\
\hline N5000-N10000 & 68 & 35.8 \\
\hline \multicolumn{3}{|l|}{ Work absence } \\
\hline Yes & 93 & 48.9 \\
\hline No & 97 & 51.1 \\
\hline \multicolumn{3}{|l|}{$N=93$} \\
\hline \multicolumn{3}{|l|}{ Duration of work absence } \\
\hline Less than 1 month & 44 & 47.3 \\
\hline 1-3 months & 23 & 24.7 \\
\hline$>3$ months & 26 & 8.0 \\
\hline \multicolumn{3}{|l|}{ Estimated cost in terms of lost hours (In Naira) } \\
\hline No cost & 21 & 22.6 \\
\hline Less than N1000 & 3 & 3.2 \\
\hline N1000-N5000 & 33 & 35.5 \\
\hline N5000-N10000 & 36 & 38.7 \\
\hline \multirow{2}{*}{$\begin{array}{l}\text { Activities respondents had difficulty in carrying out when their back pain was at } \\
\text { the worst during the past } 12 \text { months }\end{array}$} & Mild-Moderate & Severe-Extreme \\
\hline & Frequency (\%) & Frequency (\%) \\
\hline
\end{tabular}




\begin{tabular}{|l|l|l|}
\hline Walking & $109(57.4)$ & $81(42.6)$ \\
\hline Sitting & $113(59.5)$ & $77(40.5)$ \\
\hline Standing & $98(51.6)$ & $92(48.4)$ \\
\hline Lying & $98(51.6)$ & $92(48.4)$ \\
\hline Dressing & $115(60.5)$ & $75(39.5)$ \\
\hline Stooping & $103(54.2)$ & $87(45.8)$ \\
\hline Climbing stairs & $91(47.9)$ & $99(52.1)$ \\
\hline Getting out of a chair & $119(62.6)$ & $71(37.4)$ \\
\hline
\end{tabular}

(\$1 is equivalent to N365).

Table 3: Utilization of health care services.

\begin{tabular}{|c|c|c|}
\hline Variable & Frequency (N) & Percentage (\%) \\
\hline \multicolumn{3}{|l|}{$N=190$} \\
\hline \multicolumn{3}{|c|}{ Consulted any health professional to take care of LBP } \\
\hline Yes & 140 & 73.7 \\
\hline No & 50 & 26.3 \\
\hline \multicolumn{3}{|c|}{ Health professional consulted } \\
\hline General practitioner & 25 & 17.9 \\
\hline Orthopaedic doctor & 40 & 28.6 \\
\hline Physiotherapist & 71 & 50.7 \\
\hline Do not know & 4 & 2.9 \\
\hline \multicolumn{3}{|c|}{ Type of treatment received } \\
\hline Bed rest & 2 & 1.4 \\
\hline Medication & 53 & 37.9 \\
\hline Back support & 13 & 9.3 \\
\hline Exercises & 29 & 20.7 \\
\hline Electrotherapy & 37 & 28.4 \\
\hline Massage & 6 & 4.3 \\
\hline
\end{tabular}

Table 4: Associations between the prevalence of LBP, socio-demographic characteristics and job factors.

\begin{tabular}{|c|c|c|c|c|}
\hline \multirow[t]{2}{*}{ Socio-demographic characteristics } & \multicolumn{2}{|c|}{12 months prevalence of Low-back pain } & \multirow[t]{2}{*}{$x^{2}$} & \multirow[t]{2}{*}{$\boldsymbol{P}$} \\
\hline & Yes & No & & \\
\hline \multicolumn{5}{|l|}{ Age } \\
\hline $30-39$ & $44(74.6)$ & $15(25.4)$ & \multirow[t]{3}{*}{3.298} & \multirow[t]{3}{*}{0.192} \\
\hline $40-49$ & $97(77.6)$ & $28(22.4)$ & & \\
\hline $50+$ & $49(87.5)$ & $7(12.5)$ & & \\
\hline \multicolumn{5}{|l|}{ Marital status } \\
\hline Not married & $34(81.0)$ & $8(19.0)$ & \multirow[t]{2}{*}{0.098} & \multirow[t]{2}{*}{0.754} \\
\hline Married & $156(78.8)$ & $42(21.2)$ & & \\
\hline \multicolumn{5}{|l|}{ Level of education } \\
\hline Primary and Below & $32(91.4)$ & $3(8.6)$ & \multirow[t]{3}{*}{6.121} & \multirow[t]{3}{*}{0.047} \\
\hline Secondary & $118(74.7)$ & $40(25.3)$ & & \\
\hline Tertiary & $40(85.1)$ & $7(14.9)$ & & \\
\hline \multicolumn{5}{|l|}{ Type of automobile engaged in } \\
\hline Small cars & $92(77.3)$ & $27(22.7)$ & \multirow[t]{2}{*}{0.493} & \multirow[t]{2}{*}{0.483} \\
\hline Big cars & $98(81.0)$ & $23(19.0)$ & & \\
\hline
\end{tabular}




\begin{tabular}{|c|c|c|c|c|}
\hline Yes & $190(79.2)$ & $50(20.8)$ & \multirow{2}{*}{ 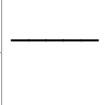 } & \multirow{2}{*}{$\longrightarrow$} \\
\hline No & $0(0.0)$ & $0(0.0)$ & & \\
\hline \multicolumn{5}{|c|}{ Lifting 5 kg } \\
\hline Yes & $152(81.7)$ & $34(18.3)$ & \multirow[t]{2}{*}{3.269} & \multirow[t]{2}{*}{0.071} \\
\hline No & $38(70.4)$ & $16(29.6)$ & & \\
\hline \multicolumn{5}{|c|}{ Lifting 25 Kg } \\
\hline Yes & $82(78.1)$ & $23(21.9)$ & \multirow[t]{2}{*}{0.130} & \multirow[t]{2}{*}{0.719} \\
\hline No & $108(80.0)$ & $27(20.0)$ & & \\
\hline \multicolumn{5}{|c|}{ Sustained sitting } \\
\hline Yes & $105(81.4)$ & $24(18.6)$ & \multirow[t]{2}{*}{0.840} & \multirow[t]{2}{*}{0.359} \\
\hline No & $85(76.6)$ & $26(23.4)$ & & \\
\hline \multicolumn{5}{|c|}{ Sustained standing } \\
\hline Yes & $126(79.2)$ & $33(20.8)$ & \multirow[t]{2}{*}{0.002} & \multirow[t]{2}{*}{0.966} \\
\hline No & $64(71.0)$ & $17(29.0)$ & & \\
\hline
\end{tabular}

Statistically significance at $P<0.05$.

Table 5: Logistic regression analysis predicting the likelihood of reporting low back pain.

\begin{tabular}{|c|c|c|c|c|}
\hline Independent variable & B & SE & Exp (B) with $95 \% \mathrm{Cl}$ & $P$ \\
\hline \multicolumn{5}{|l|}{ Age } \\
\hline $30-39$ & & & 1 & \\
\hline $40-49$ & -0.09 & 0.38 & $0.92(0.44$ to 1.92$)$ & 0.82 \\
\hline $50+$ & -0.81 & 0.51 & $0.45(0.17$ to 1.21$)$ & 0.11 \\
\hline \multicolumn{5}{|l|}{ Level of education } \\
\hline Primary and Below & -0.63 & 0.74 & $0.53(0.13$ to 2.25$)$ & 0.39 \\
\hline Secondary & 0.59 & 0.45 & $1.80(0.74$ to 4.37$)$ & 0.20 \\
\hline Tertiary & & & 1 & \\
\hline \multicolumn{5}{|l|}{ Lifting $5 \mathrm{~kg}$} \\
\hline Yes & & & 1 & \\
\hline No & 0.56 & 0.36 & 1.75 (0.86 to 3.56$)$ & 0.12 \\
\hline
\end{tabular}

Statistically significance at $P<0.05$.

(8.9\%). The mean pain intensity of participants in the past seven days was $5.95 \pm 1.61 \mathrm{~cm}$ (range $1-9 \mathrm{~cm}$ ).

At the bivariate level, there was no significant association between prevalence of LBP and each of age $\left(\chi^{2}=\right.$ 3.298, $P=0.192)$, marital status $\left(\chi^{2}=0.098, P=0.754\right)$, type of automobile repairs engaged in $\left(\chi^{2}=0.493, P=\right.$ $0.483)$, lifting objects up to $5 \mathrm{~kg}\left(\chi^{2}=3.269, \mathrm{p}=0.071\right)$, lifting objects up to $25 \mathrm{~kg}\left(\chi^{2}=0.130, p=0.719\right)$, sustained sitting $\left(\chi^{2}=0.840, p=0.349\right)$, and sustained standing $\left(\chi^{2}\right.$ $=0.002, p=0.996)$, However, there was a significant association between level of education and the prevalence of $\operatorname{LBP}\left(\chi^{2}=6.121, p=0.047\right)$ (Table 4).

Multivariate logistic regression did not show any significance between the prevalence of LBP, age and lifting objects up to $5 \mathrm{~kg}$ (Table 5).

\section{Discussion}

The findings of this study revealed that work-related LBP is a significant health problem among automobile technicians. The LBP prevalence of $79.2 \%$ in the present study was higher than $44.3 \%$ reported by Phillip, et al. [23] and 62.8\% reported by Tamene, et al. [24] among automobile workers in Southern India and Southern Ethiopia, respectively. Conversely, the prevalence of LBP reported by the automobile in this study was lower than the $80.4 \%$ reported among their counterparts in Eastern Nigeria [1]. The varying results between the present study and the study by Abaraogu, et al. [1] may be as a result of the heterogeneity of their sample (comprising panel beating, wheel alignment, electrical works, repairs and servicing). It is adducible that the high physical strength demand of automobile mechanic duties predisposed them to high rates of LBP. Previous investigators have confirmed a significant association between increased physical demand and risk of LBP $[4,25,26]$.

The high rate of absenteeism, defined as the absence of a worker from their work-place during a typical day's work schedule [27], found in this study is an indicator of heightened disability among automobile technicians. LBP is the largest contributor to absenteeism caused by musculoskeletal problems [28]. The prevalen- 
ce rate of absenteeism in this study is higher than that of a previous study among automobile factory workers [29]. Abaraogu, et al. [1] also found that about half of automobile technicians who had LBP were prevented from doing their usual activities.

Automobile technicians with LBP in this study reported difficulty with climbing stairs, standing and lying down. LBP as a debilitating condition interferes with normal functioning and activities of daily living [30,31]. Previous studies have reported that individuals with LBP often have difficulties in climbing stairs and standing but find relief for their back pain while lying down [30,31]. The automobile technicians in this study found it challenging to maintain lying position, as some of their daily jobs require lying on their backs often, maintain such working positions during an active episode of LBP may be quite difficult.

The finding of this study shows that $40 \%$ and $35.8 \%$ of automobile technicians who developed LBP had incurred about N1000-N5000 and N5000-N10000, respectively as treatment cost. Also, having LBP led to loss of productivity of about N1000-N5000 and N5000-N10000 respectively by $35.5 \%$ and $38.7 \%$ of the automobile technicians. N1000-N5000 and N5000-N10000 translate to $\$ 2.74-\$ 13.7$ and $\$ 13.7-\$ 27.4$ respectively. Reflective on the study context where out-of-pocket payments for health care is the practice, especially among blue-collar workers, health care service for automobile technicians seems not affordable, as most Nigerians earn less than one dollar a day. It is adducible that consideration for the cost of treatment may have accounted for the $26.3 \%$ of automobile technicians who did not seek health professional to take care of LBP. Eme Ichoku and Leibbrandt [32] found that a formal and informal user fee, which vary according to the kind of treatment sought and the level of the facility utilised, is charged in health care facilities in Nigeria. Also, Mbada, et al. [33] found a willingness to pay rate of $41.7 \%$ for physiotherapy session among a population of Nigerians that earn between N15,000 and N50,000 monthly. The study highlights that within the range of earnings, willingness to pay the sum of N5,000 for LBP treatment translates to $10 \%$ and $33.3 \%$ spending from a high and low earner, respectively. It is reasonable that the burden of cost of care for every treatment based on the out-of-pocket spending may encourage alternative health care seeking among automobile technicians in this study.

Majority of the automobile technicians in this study sought the services of physiotherapists to manage their LBP. This finding is in contrast to the study by Abaraogu, et al. [1], where self-treated and over-the-counter drugs where commonly used to manage LBP among automobile technicians. It is possible that these individuals' health problem is of severity that is beyond coping and self-treated, thus making them seek health care. Otherwise, anecdotal evidence suggests that self-medi- cation and use of alternative care for musculoskeletal pain is a common phenomenon in the setting where this study was conducted, especially among blue-collar workgroup. Also, patronage of physiotherapy by automobile technicians in this study may suggest increase awareness of the role of physiotherapy in pain management. Patronage of physiotherapy among these individuals may be cost-saving. Frogner, et al. [34] submit that an individual with LBP whose first contact health provider was a physiotherapist may likely have a lower opioid prescription; no advanced imaging investigation and lower out-of-pocket costs that those who never or later saw a physiotherapist. Another finding from this study indicates that neither socio-demographic characteristics nor work activities were associated with the prevalence of LBP. It is implied that physical exertion and other manual demands of the job predispose to LBP. In sum, a large number of automobile technicians experience work-related LBP. Therefore, it is pertinent that automobile associations, health policymakers and regulatory bodies consider ergonomic and safety education interventions that will address the hazardous effects of engaging in automobile mechanics job.

In view of apparent dearth of occupation-specific tool to assess musculoskeletal disorders among automobile technicians, the Bindra, et al. [21] questionnaire for low back pain in the garment industry workers was adapted in this study and was evaluated for face validity by experts. Though the Bindra, et al. [21] questionnaire had acceptable internal consistency and moderate to high test re-test reliability, lack of findings on its external validity to other occupational populations, such as automobile technicians is a significant limitation of this study. Furthermore, information on anthropometric characteristics involving body mass index, lifestyle habits (e.g. smoking) and health conditions (e.g. diabetes mellitus), and other work characteristics such as duration of hours of work in a week and month which could have strong association with LBP prevalence and influence the result were not obtained in this study. Therefore, future studies are needed to explore these limitations and validate the findings of this study.

\section{Conclusion}

There is a high prevalence of LBP among Nigerian automobile technicians, and it results in work absenteeism, economic burden and increased need to seek health care. While automobile specific activities requiring frequent bending, lifting heavy objects and sustained postures in sitting or standing did not significantly influence prevalence of LBP, education as a socio-demographic factor was significantly associated with LBP prevalence among them. However, the saliency of the association between level of education and the prevalence of LBP is in fact based on the multiple testing of each factor and prevalence of LBP, but may not survive in the multiple corrections. 


\section{Acknowledgement}

We appreciate all the automobile technicians who took part in this study.

\section{Declarations}

\section{Conflicts of interest/Competing interests}

The authors declare no conflicts of interest/competing interests.

\section{Availability of data and material}

The data and materials used for this research are available on request.

\section{Code availability}

Not applicable.

\section{Ethics approval}

Approval was obtained from the Health Research and Ethics Committee (IPHOAU/12/723) of the Institute of Public Health, Obafemi Awolowo University, Ile-Ife, Nigeria. The procedures used in this study adhere to the tenets of the Declaration of Helsinki.

\section{Consent to participate}

Informed consent was obtained from all individual participants included in the study.

\section{Consent for publication}

Patients signed informed consent regarding publishing their data and photographs.

\section{Authors' contributions}

[Concept development: O.A.O, M.C.E, F.F; Design (planned the methods to generate the results): O.A.O, M.C.E. I.O.A, O.T; Supervision (provided oversight, responsible for organization and implementation, writing of the manuscript): O.A.O, M.C.E, F.F; Data collection/ processing (responsible for experiments, organization, or reporting data): M.H, S.A, I.O.A, O.T; Analysis/interpretation (responsible for statistical analysis, evaluation, and presentation of the results): O.A.O, M.C.E, O.T, $M / H, I . O . A, F . F$; Literature search (performed the literature search): O.T, O.A.O; Writing (responsible for writing a substantive part of the manuscript): O.A.O, M.C.E, O.T. M.H. I.O.A; Critical review (revised manuscript for intellectual content, this does not relate to spelling and grammar checking): O.A.O, F.F, M.C.E, S.A, I.O.A; Approval of final draft: O.A.O, M.B.E, O.T, M.H, I.O.A, S.A, F.F].

\section{Funding}

The research was self-funded by authors.

\section{References}

1. Abaraogu UO, Ezema Cl, Igwe SE, Egwuonwu AV, Okafor UC (2016) Work-related back discomfort and associated factors among automotive maintenance mechanics in Eastern Nigeria: A cross sectional study. Work 53: 813-823.
2. Hartvigsen J, Hancock MJ, Kongsted A, Louw Q, Ferreira $M L$, et al. (2018) What low back pain is and why we need to pay attention. Lancet 391: 2356-2367.

3. GBD 2016 DALYs, HALE Collaborators (2017) Global, regional, and national disability-adjusted life-years (DALYs) for 333 diseases and injuries and healthy life expectancy (HALE) for 195 countries and territories, 1990-2016: A systematic analysis for the Global Burden of Disease Study 2016. Lancet 390: 1260-1344.

4. Serranheira F, Sousa-Uva M, Heranz F, Kovacs F, Sousa-Uva A (2020) Low Back Pain (LBP), work and absenteeism. Work 65: 463-469.

5. Vos T, Barber RM, Bell B, Bertozzi-Villa A, Biryukov S, et al. (2015) Global, regional, and national incidence, prevalence, and years lived with disability for 301 acute and chronic diseases and injuries in 188 countries, 1990-2013: A systematic analysis for the Global Burden of Disease Study 2013. Lancet 386: 743-800.

6. Tinubu BMS, Mbada CE, Oyeyemi AL, Fabunmi AA (2010) Work-related musculoskeletal disorders among nurses in Ibadan, South-west Nigeria: A cross-sectional survey. BMC Musculoskelet Disord 11: 12.

7. Mehra M, Hill K, Nicholl D, Schadrack J (2012) The burden of chronic low back pain with and without a neuropathic component: A healthcare resource use and cost analysis. J Med Econ 15: 245-252.

8. Oberlinner C, Yong M, Nasterlack M, Pluto RP, Lang S (2015) Combined effect of back pain and stress on work ability. Occup Med (Lond) 65: 147-153.

9. Yabe $Y$, Hagiwara $Y$, Sekiguchi T, Momma H, Tsuchiya $M$, et al. (2020) Association between lower back pain and lower extremity pain among young volleyball players: A cross-sectional study. Phys Ther Sport 43: 65-69.

10. National Institute for Occupational Safety and Health (NIO$\mathrm{SH})$ (2013) Quality of work life questionnaire. Washington, DC, USA.

11. da Costa BR, Vieira ER (2010) Risk factors for work-related musculoskeletal disorders: A systematic review of recent longitudinal studies. Am J Ind Med 53: 285-323.

12. Tella BA, Akinbo SRA, Asafa SA, Gbiri CA (2013) Prevalence and impacts of low back pain among peasant farmers in south-west Nigeria. Int J Occup Med Environ Health 26: 621-627.

13. Keawduangdee $P$, Puntumetakul R, Swangnetr M, Laohasiriwong W, Settheetham D, et al. (2015) Prevalence of low back pain and associated factors among farmers during the rice transplanting process. J Phys Ther Sci 27: 2239-2245.

14. Boschman JS, van der Molen HF, Sluiter JK, Frings-Dresen $\mathrm{MH}$ (2012) Musculoskeletal disorders among construction workers: A one-year follow-up study. BMC Musculoskelet Disord 13: 196.

15. Machado Susseret N, Briceno-Ayala L, Radon K (2019) Prevalence of low back pain in migrant construction workers in Mar del Plata, Argentina. Am J Ind Med 62: 777-782.

16. Kamoun S, Allagui I, Bouzgarrou L, Rassas I, Omrane A, et al. (2015) Low back pain in healthcare: Study among 300 health care workers of two University Hospitals in the center of Tunisia. Ann Phys Rehabil Med 58: e90.

17. Mehrdad R, Shams-Hosseini NS, Aghdaei S, Yousefian MD (2016) Prevalence of low back pain in health care workers and comparison with other occupational Categories in Iran: A systematic review. Iran J Med Sci 41: 467-478. 
18. Omokhodion FO, Osungbade OO (1996) Health problems of automobile mechanics in Nigeria. Trop Doct 26: 102-104.

19. Torp S, Riise T, Moen BE (2001) The impact of psychosocial work factors on musculoskeletal pain: A prospective study. J Occup Environ Med 43: 120-126.

20. Cochran WG, Chambers SP (1964) The planning of observational studies of human populations. J Royal Stat Soc A 128: $234-266$

21. Bindra S, Sinha AGK, Benjamin Al (2013) Questionnaire for low back pain in the garment industry workers. Indian J Occup Environ Med 17: 48-57.

22. Langley GB, Sheppeard H (1985) The visual analogue scale: Its use in pain measurement. Rheumatol Int 5: 145-148.

23. Philip M, Alex RG, Sunny SS, Alwan A, Guzzula D, et al. (2014) A study on morbidity among automobile service and repair workers in an urban area of South India. Indian $\mathrm{J}$ Occup Environ Med 18: 9-12.

24. Tamene A, Mulugeta H, Ashenafi T, Thygerson SM (2020) Musculoskeletal disorders and associated factors among vehicle repair workers in Hawassa City, Southern Ethiopia. J Environ Public Health 2020: 9472357.

25. Hestbaek L, Korsholm L, Leboeuf-Y C, Kyvik KO (2008) Does socioeconomic status in adolescence predict low back pain in adulthood? A repeated cross-sectional study of 4,771 Danish adolescents. Eur Spine J 17: 1727-1734.

26. Bláfoss R, Skovlund SV, López-Bueno R, Calatayud J, Sundstrup E, et al. (2020) Is hard physical work in the early working life associated with back pain later in life? A cross-sectional study among 5700 older workers. BMJ Open 10: e040158

27. Silva A, Ramos AL, Brito M, Ramos A (2020) A diagnostic analysis of Absenteeism-A case study in a Portuguese cork industry. In: Arezes P, Occupational and environmental safety and health II. Studies in Systems, Decision and Control 277: 793-799.

28. Hubertsson J, Englund M, Hallgårde U, Lidwall U, Löfvendahl S, et al. (2014) Sick leave patterns in common musculoskeletal disorders - a study of doctor prescribed sick leave. BMC Musculoskelet Disord 15: 176.

29. Mehrdad R, Pouryaghoub G, Afsah MM (2020) Association between absenteeism and low back pain in an automobile factory. SN Compr Clin 2: 278-283.

30. Yiengprugsawan V, Hoy D, Buchbinder R, Bain C, Seubsman SA, et al. (2017) Low back pain and limitations of daily living in Asia: Longitudinal findings in the Thai cohort study. BMC Musculoskelet Disord 18: 19.

31. Spenkelink CD, Hutten MMR, Hermens HJ, Greitemann BOL (2002) Assessment of activities of daily living with an ambulatory monitoring system: A comparative study in patients with chronic low back pain and nonsymptomatic controls. Clin Rehabil 16: 16-26.

32. Eme Ichoku H, Leibbrandt M (2003) Demand for healthcare services in Nigeria: A multivariate nested logit model. Afr Dev Rev 15: 396-424.

33. Mbada CE, Mamud SO, Odole AC, Omole JO, Oyewole OO, et al. (2019) Development and clinimetric testing of willingness to pay tool for physiotherapy. Phys Ther Rev 24: 134-142.

34. Frogner BK, Harwood K, Andrilla CHA, Schwartz M, Pines JM (2018) Physical therapy as the first point of care to treat low back pain: An instrumental variables approach to estimate impact on opioid prescription, health care utilization, and costs. Health Serv Res 53: 4629-4646. 